\title{
STRUCTURE OPTIMIZATION OF WHEEL ON FATIGUE FAILURE
}

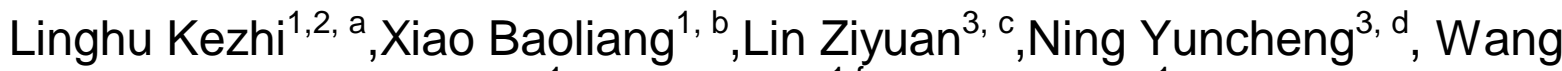 \\ Fengqin $^{1, \mathrm{e}}$, Li Shaobo ${ }^{1, \mathrm{f}}$,Huang Xueqi ${ }^{1, \mathrm{~g}}$ \\ ${ }^{1}$ Research Institute of Technology of Shougang Group,Beijing 100043,China \\ ${ }^{2}$ Beijing Key Laboratory of Green Recycling Process for Iron \& Steel Production Technology, Beijing \\ 100043, China \\ ${ }^{3}$ Research Center of Zhengxing Wheel Group,Zhangzhou 363000,China \\ abjlhkz@139.com, bblx@163.com, 'Linzy@163.com, 'Nyuncheng@sina.com, \\ 'Wfengqin@shougang.com, 'lishaobolq@163.com,Huangxq@163.com
}

\begin{abstract}
Keywords: fatigue failure, abaqus, wheel, structure, optimization
Abstract. Based on the basic truck steel wheel structure design, revised designs such as vent-hole-changed and profile-modified were proposed to solve the common fatigue failure problems .Both basic and modified design were modeled using Abaqus 3D software to calculate the stress and strain contours in the case of bending load and radial load, consequently fatigue life contours of models for each load case were calculated with the help of Brown-Miller biaxial fatigue theory. It was shown by the research that shape-optimization of wheel profile, increasing volume by $2.4 \%$, can extend both the bending fatigue life and the radial fatigue life by $73.8 \%$ and $289 \%$ respectively.
\end{abstract}

\section{Introduction}

Vehicle wheel is a critical component that bears the auto-body weight and load weight, which is mainly structured by wheel disc and rim. Structural design is a vital part of the whole automobile industry to ensure that wheels work in the normal condition without earlier fatigue failure[1-4]. Moreover, the safety and stability of an operating vehicle are largely attributed to superior stiffness, elastic property and fatigue performance. Several complex operating conditions are inevitably introduced while driving, resulting that the wheel simultaneously suffers several loads from various directions. Some of them may generate stress on the wheel that is beyond a certain range, which as a consequence possibly leads to the structural failure[1]. The failure modes of wheels are mainly divided into 2 categories, strength failure and fatigue failure, and above $80 \%$ are induced related to the latter mode. Therefore, it is significantly important to investigate in its fatigue failure mode[5-6]. Safety is always the primary consideration of current international advanced wheel design, highlighting the significance of the strength and fatigue life of the wheel[7-8].

Fatigue fracture, acting as a main cause of the failure of wheel, is a kind of typical high-cycle fatigue[1]. In consideration of the importance of fatigue life, previous work has taken special research in the fatigue testing machine[9]. With the rapid development of computer technology, CAD/CAE techniques are widely used in industrial design and manufacturing process[10,11]. Applying the simplified model without considering the effect of circumferential position variation of loads, stress-strain distribution and fatigue life of the wheel can be easily simulated with a computer, which considerably improves the efficiency of product design and reduces the development cost[12-15]. A precondition for using simulation technique to calculate the fatigue and optimize the structure is that a precise enough stress-strain distribution is required. Thus, in order to further improve the accuracy of the simulating calculation, this work has made improvements in the finite element modeling analysis process based on the previous research: 1. Assembly of a certain type of wheel and bolts has been modeled, with considering the effect of pre-tightening force, thus the calculation precision of regions near to the bolt holes has been enhanced; 2 . Under the radial load condition, integral modeling of the wheel rim has been proposed, achieving the actual stress state of the wheel in operating conditions; 3 . In consideration of the discrete distribution of bolt and vent holes along the circumference, 
multiposition calculation (every $90^{\circ}$ set a calculation in this paper) has been applied for the solving process of bending and radial loads; 4. After analysis of the stress-strain distribution under both bending and radial loads, Brown-Miller biaxial fatigue model has been applied and fatigue life contour has been figured out. Furthermore, via comparing the fatigue life of wheels with various structures, structural optimization of this type of wheel has been achieved, improving its fatigue life.

\section{Fatigue failure of wheels}

A certain type of wheel without tube is shown in Figure 1(a), assembled by a drop-slot rim and a metal spinned disc. The center part of the wheel has 10 bolt holes and a center hole. The disc is connected to the hub by bolts. The center hole is used for centering location of the wheel, making sure that the center lines of the wheel and hub are coaxial. The edge of the disc is connected with the rim by welding, and several vents are set at the lateral of the disc. For this type of wheel, fatigue fractures normally appear at vicinity of bolt and vent holes, or at the joint areas (shown in Figure 1(b), (c) and (d), respectively).

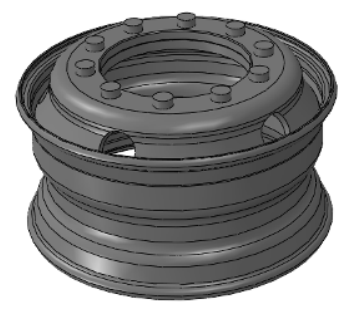

(a) schematic diagram
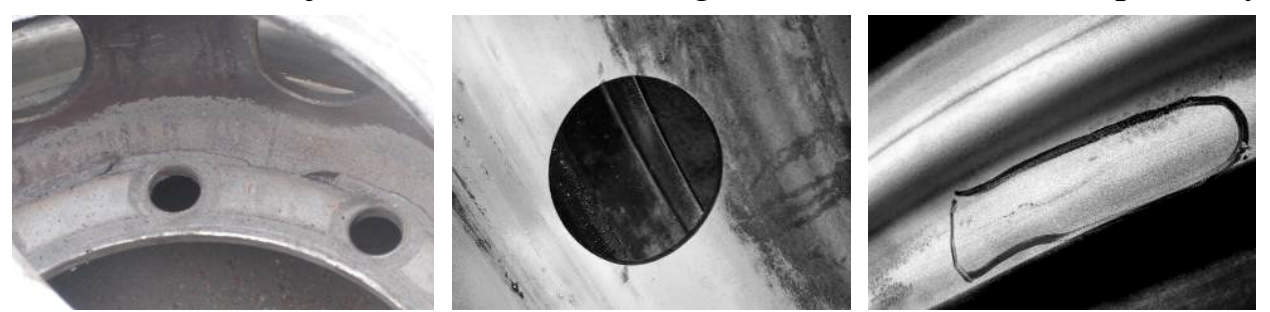

Fig. 1 common fatigue failure of a certain type of wheel

\section{Structural optimization and FEM calculation}

\section{Basic structure of wheel}

A wheel is generally composed of a disc and a rim. The rim provides a stage for installation of wheel tube, and the disc is jointed with the hub via bolts. As the thickness of the disc gradually tends to thin from its bottom to the edge, a reasonable distribution of materials can be obtained after metal spinning, resulting that the whole structure is of a constant strength but various cross-sections. This metal spinned disc has the advantages of high dimensional precise, superior surface quality, good balance and light weight[9]. The cross-section outline and 3D structure of a certain wheel are illustrated in Figure 2(a) and 2(b), respectively.

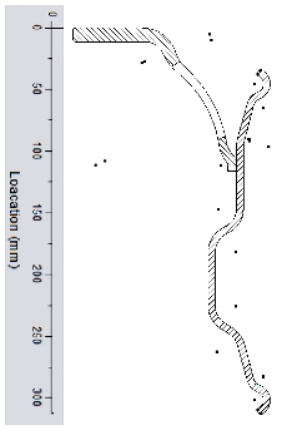

(a)cross-section of wheel

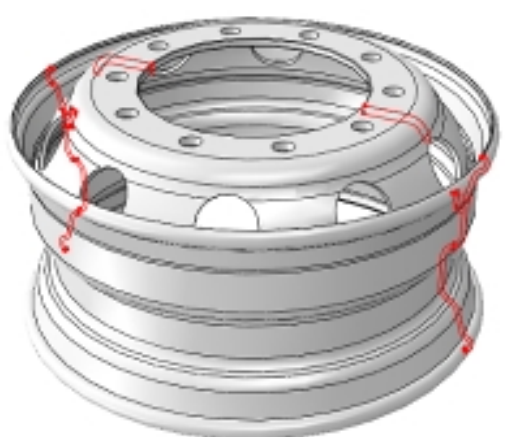

(b)3D model of wheel

\section{Structural optimization of wheel}

Fig. 2 the cross-section view and 3D model of wheel

Under the condition that the wheel rim remains unchanged, the disc structure has been optimized by adjustment of the vent number and the cross-sectional structures in this work. 3 design schemes have been put forward as follow. Optimized A model: with the basic cross-sectional structure, the number of vents has increased from 5 to 10; Optimized B model: the cross-sectional area of the disc has been reduced with the basic structure; Optimized $\mathrm{C}$ model: the cross-sectional area has been thickened from 
the basic structure. The cross-sectional areas and volume parameters of the basic structure and each scheme have been shown in table 1.

Table1 Comparison of basic and 3 optimized schemes

\begin{tabular}{l|c|c|c|c|}
\hline Basic model & Optimized A & Optimized C \\
\hline & & & \\
\hline
\end{tabular}

\section{Computing standards and loading conditions}

According to "Performance requirements and test methods of commercial vehicles wheels" (GB/T 5909-2009), the fatigue life has been assessed by the verification of dynamic bending fatigue and radial load (shown in Figure 3).
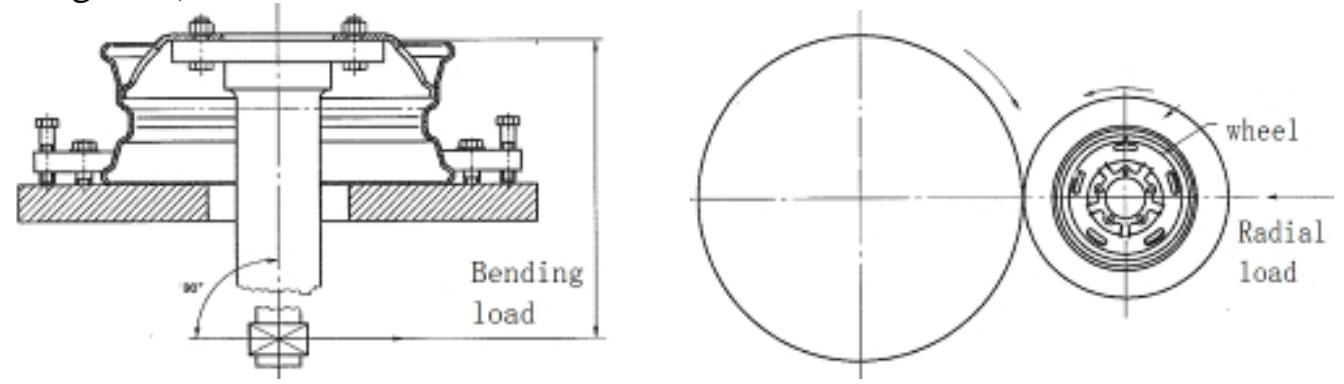

(a)schematic diagram of bending load (b)schematic diagram of radial load

Fig.3 schematic diagrams of fatigue failure test of vehicle wheel

Referring to the requirements of GB/T 5909-2009, the finite element model has been established. Elastic modulus of the material used is $206000 \mathrm{MPa}$ and the Poisson ratio is 0.3 . The stress-strain curve of the material is shown in Figure 4.

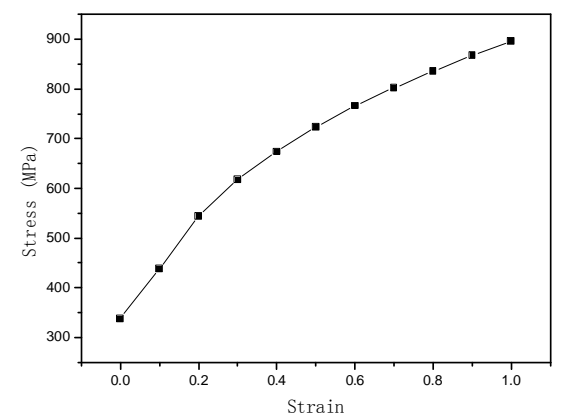

Fig.4 stress-strain curve of wheel material

Based on the national standard "Hexagon socket head cup screws" (GB/T 70.1-2000), M22 bolts with the washer diameter of $40 \mathrm{~mm}$ have been chosen in this work. The torque of bolts is $610 \mathrm{~N} . \mathrm{m}$ and the pre-tightening force coefficient chosen is 0.3[9]. The pre-tightening force has been calculated as around $50833 \mathrm{~N}$. The bending torque and radial load are $35 \mathrm{KN} . \mathrm{m}$ and $90 \mathrm{KN}$, respectively. 

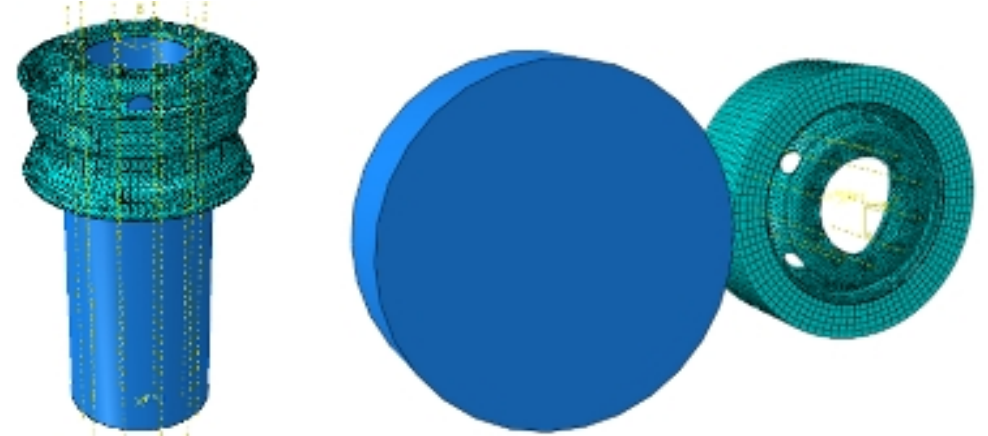

Fig.5 FEM model of bending and radial load of wheel

Finite element modeling of each type wheel has been implemented by using the FEM software Abaqus. The basic mode has been meshed into 35819 elements and 65529 nodes; Optimized A mode has 33144 elements and 60315 nodes; Optimized B mode has 35933 elements and 65873 nodes; Optimized C mode has 35213 elements and 64445 nodes.

\section{Analysis of bending torque and radial load}

Under $35 \mathrm{KN}$.m bending torque, the stress contour and the maximum stresses on critical areas of each mode are shown in Table 2.

Table 2 Stress contour of wheels under bending load

\begin{tabular}{|c|c|c|c|c|}
\hline Item & Basic model & Optimized A & Optimized B & Optimized C \\
\hline $\begin{array}{l}\text { Stress } \\
\text { contour }\end{array}$ & & & & \\
\hline $\begin{array}{l}\text { Max. } \\
\text { stress }\end{array}$ & $\begin{array}{l}\text { Bolt hole:350MPa } \\
\text { Vent:112 MPa } \\
\text { Welding: } 85 \mathrm{MPa}\end{array}$ & $\begin{array}{l}\text { Bolt hole: } 176 \mathrm{MPa} \\
\text { Vent:113 MPa } \\
\text { Welding:90 MPa }\end{array}$ & $\begin{array}{l}\text { Bolt hole:226 MPa } \\
\text { Vent:127 MPa } \\
\text { Welding:95 MPa }\end{array}$ & $\begin{array}{l}\text { Bolt hole:199 MPa } \\
\text { Vent:127 MPa } \\
\text { Welding:76 MPa }\end{array}$ \\
\hline
\end{tabular}

Under $90 \mathrm{KN}$ radial load, the stress contour and the maximum stresses on critical areas of each mode are shown in Table 3.

Table 3 Stress contour of wheels under radial load

\begin{tabular}{|c|c|c|c|c|}
\hline Item & Basic model & Optimized A & Optimized B & Optimized C \\
\hline $\begin{array}{l}\text { Stress } \\
\text { contour }\end{array}$ & & & & \\
\hline $\begin{array}{l}\text { Max. } \\
\text { stress }\end{array}$ & $\begin{array}{l}\text { Bolt hole: } 202 \mathrm{MPa} \\
\text { Vent: } 86 \mathrm{MPa} \\
\text { Welding:40 MPa }\end{array}$ & $\begin{array}{l}\text { Bolt hole: } 145 \mathrm{MPa} \\
\text { Vent:101 MPa } \\
\text { Welding:44 MPa }\end{array}$ & $\begin{array}{l}\text { Bolt hole:146 MPa } \\
\text { Vent:97 MPa } \\
\text { Welding:42 MPa }\end{array}$ & $\begin{array}{l}\text { Bolt hole: } 198 \mathrm{MPa} \\
\text { Vent:128 MPa } \\
\text { Welding:74 MPa }\end{array}$ \\
\hline
\end{tabular}

\section{Fatigue life analysis based on stress condition}

In general operating condition, the wheel is simultaneously subject to bending and radial loads, thus the stress state belongs to multi-axial stress. Multi-axial fatigue is also termed as biaxial fatigue, which is different from uniaxial fatigue that cracks normally first appear on the component surface under multi-axial stresses[16]. Brown-Miller fatigue law, a critical plane approach, states that generation of fatigue cracks has certain directionality, showing that fatigue cracks first appear at the plane subject to 
the maximum shearing strain[17]. Due to the actual physical significance of this law, it is widely applied as a prediction method for multi-axial fatigue life[18].

\section{Brown-Miller fatigue law}

Based on the results of elastic FEM calculation, the stress history of any node can be obtained. With the principal stress, the relevant principal strain can be figured out according to generalized Hooke law, thus the time history of the shearing strain and normal strain can be further calculated.

$$
\frac{\Delta \gamma}{2}+\frac{\Delta \varepsilon_{n}}{2}=1.65 \frac{\sigma_{f}^{\prime}}{E}\left(2 N_{f}\right)^{b}+1.75 \varepsilon_{f}^{\prime}\left(2 N_{f}\right)^{c}
$$

After correction of the mean stress:

$$
\frac{\Delta \gamma}{2}+\frac{\Delta \varepsilon_{n}}{2}=1.65 \frac{\left(\sigma_{f}^{\prime}-\sigma_{m}\right)}{E}\left(2 N_{f}\right)^{b}+1.75 \varepsilon_{f}^{\prime}\left(2 N_{f}\right)^{c}
$$

where $\Delta \gamma$ is the shearing strain; $\Delta \varepsilon n$ is the value of shearing strain in the normal direction.

\section{Calculation of fatigue life under bending and radial load}

According to Brown-Miller fatigue law, the bending and radial stress distributions have been obtained by FEM calculation. With such results, the multi-axial fatigue life contour of each mode has been calculated, shown in Table 4.

Table 4 Fatigue contours of wheels under bending and radial load

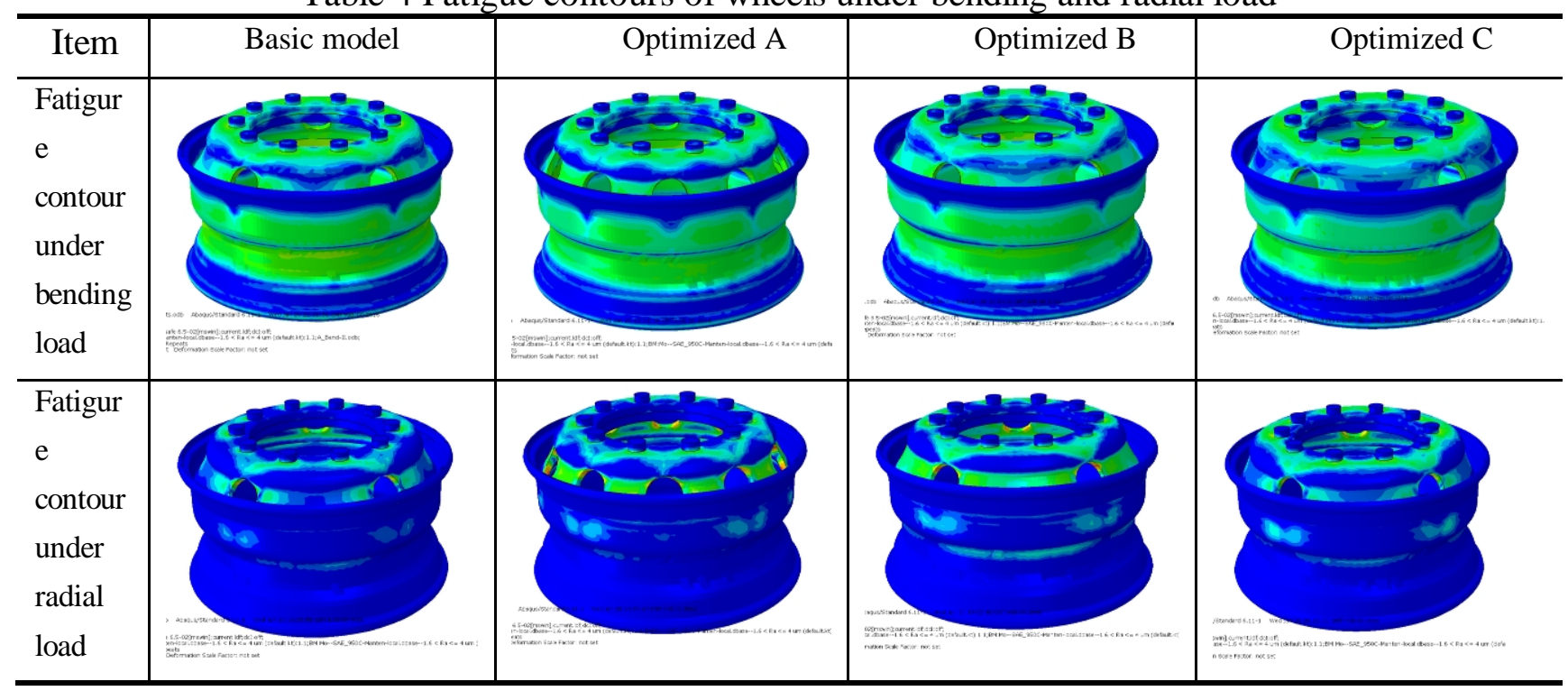

By analyzing the fatigue life contour of each mode, it is concluded as follow:

1) Under the bending load, the critical parts of the rim have been identified as the slot zone. In addition, some other potential failure regions have been observed periodically appearing in the disc/rim welded zones facing the vents. Under the radial load, the potential failure regions are also concentrated in both the slot and disc/rim welded regions.

2) Under the bending load, the bending area adjacent to the bolt holes of the disc becomes the potential region of fatigue failure, which has the trend extending to the vents. Meanwhile, similar result has been obtained under the radial load.

3) Under both bending and radial loads, fatigue fracture greatly tends to appear at regions adjacent to bolt holes and vent holes.

\section{Analysis and Comparison of fatigue life}

According to the calculated results of bending fatigue life and radial fatigue life, the life index of each optimized mode has been plotted against the location of cross-section. Comparisons of the life index of each optimized mode with the basic structure have been shown in Figure 6, with shadow areas indicating the life index distribution related to optimized modes and solid lines representing the distribution of the basic mode. 


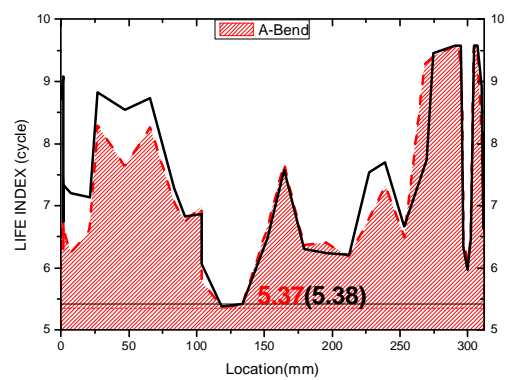

(a) fatigue life index of optimized A under bending

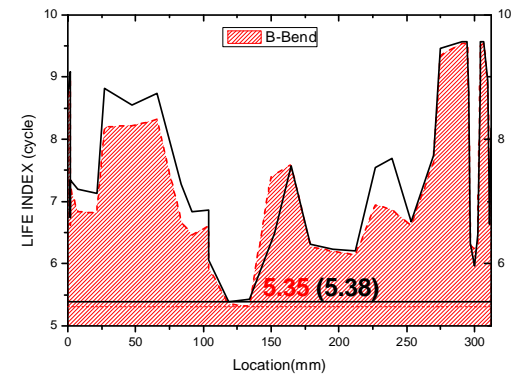

(c) fatigue life index of optimized B under bending

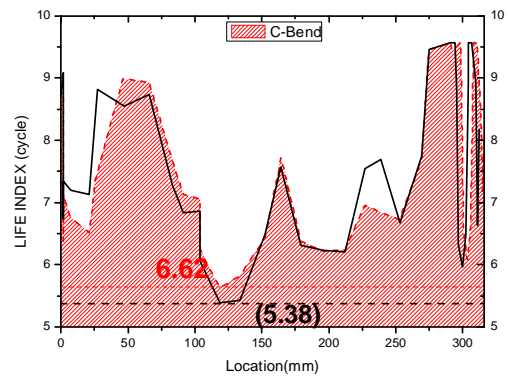

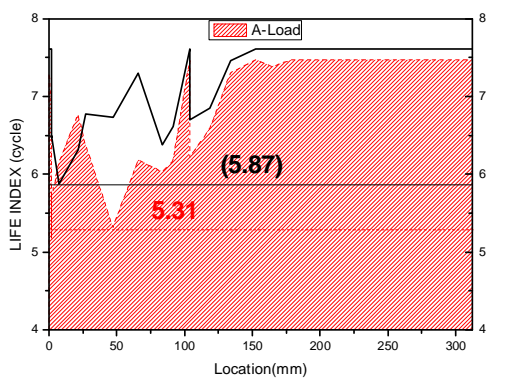

(b) fatigue life index of optimized A under radial load

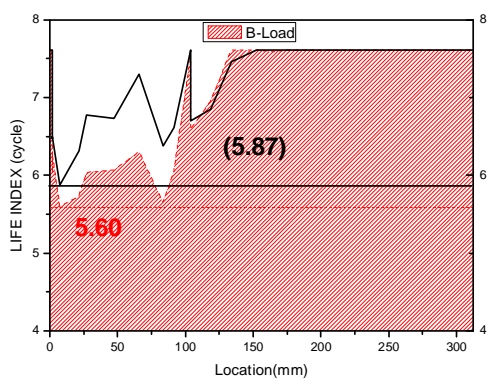

(d) fatigue life index of optimized B under radial load

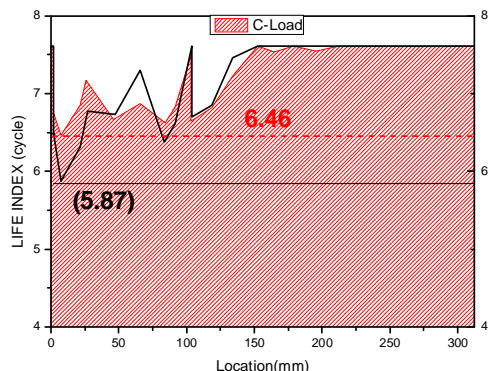

(e) fatigue life index of optimized $\mathrm{C}$ under bending (f) fatigue life index of optimized $\mathrm{C}$ under radial load

Fig. 6 comparison of fatigue life index of basic and optimized models

From the life index distribution, it is observed that the bending fatigue life index of basic structure is 5.38, which of the optimized structures are 5.37, 5.35 and 5.62, respectively; for radial fatigue, the life index of basic structure is 5.87, which of the optimized structures are 5.31, 5.60 and 6.46, respectively.

\section{Conclusions}

Aiming to alleviate the fatigue fracture issue of a certain type of truck wheel, this paper presents three proposals through modifying the number of vent and geometric structure of disc cross-section. In this paper, 3D modeling and finite element method were used to calculate bending/radial load stress of both basic and optimized structures. Then Brown-Miller multi-axial fatigue model was applied to calculate bending/radial load fatigue life of each structure. After analyzing and comparing fatigue life distribution of wheel with various cross sections, the following conclusions have been proposed:

1. Under the condition that the wheel material and cross-sectional area remain unchanged, bending fatigue life was shortened from $10^{5.38}$ to $10^{5.37}(2.3 \%)$ when the number of disc vents increased from 5 to 10 (volume reduced from $0.0082 \mathrm{~m}^{3}$ to $0.008 \mathrm{~m}^{3}, 2.4 \%$ ). In addition, radial fatigue life was reduced by $74.2 \%$ (from $10^{5.87}$ to $10^{5.31}$ ).

2. Under the condition that the wheel material and number of disc vents remain unchanged, bending fatigue life was reduced by $6.7 \%$ (from $10^{5.38}$ to $10^{5.35}$ ) when cross-sectional area decreased from $3087 \mathrm{~mm}^{2}$ to $2790 \mathrm{~mm}^{2}$ (volume reduced from $0.0082 \mathrm{~m}^{3}$ to $0.008 \mathrm{~m}^{3}, 2.4 \%$ ). Meanwhile, radial fatigue life was shortened by $46.3 \%$ (from $10^{5.87}$ to $10^{5.60}$ ). 
3. Under the condition that the wheel material and number of disc vents remain unchanged, bending fatigue life was prolonged from $10^{5.38}$ to $10^{5.62}(73.8 \%)$ when cross-sectional area increased from $3087 \mathrm{~mm}^{2}$ to $3193 \mathrm{~mm}^{2}$ (volume expanded from $0.0082 \mathrm{~m}^{3}$ to $0.0084 \mathrm{~m}^{3}, 2.4 \%$ ). Meanwhile, radial fatigue life was also increased by $289 \%$ (from $10^{5.87}$ to $10^{6.46}$ ).

\section{References}

[1] L.Ming:Anti-Fatigue Design of Auto Structure. Hefei: Press of University of Science and Technology, 1995

[2] Z.Kun,Z.Yutao,S.Dawei:Cornering fatigue capability analysis of aluminum alloy automotive wheels based on finite element analysis. Machinery Design \& Manufacture, 2009,(5),6-7

[3] Y.Zhisheng:Theories of Automobile. Beijing: China Machine Press, 1998

[4] W.Xiaofeng,W.Bo,Z.Zhenwei:Structure strength analysis of automotive wheels. Journal of Mechanical Strength , 2002,24(1),66-69

[5]H.M.Karandikar:Fatigue life prediction for wheels by simulation of the rotating bending test.SAE900147,180-190

[6] L. Chenzhao,G.Yongjin,Z. Ping:Research on factors influencing fatigue life of steel wheel in cornering test. Machine Design and Research, 2011(4),44-47,51

[7] Y.Jinyan:Finite element analysis of an aluminum alloy wheel based on bending and radial fatigue test.[Master Thesis].Guangzhou: South China University of Technology.2013

[8]W.Yongshan, W.Bin:FEA and lightweight on aluminum alloy wheel hub. Auto Engineers,2013,(4): $32-33,62$

[9]M.Fanyi:Research on the wheel dynamic bending fatigue test machine.[Master Thesis].Changchun: Changchun University of Science and Technology.2013

[10] M. Firat:Numerical modeling and simulation of wheel radial fatigue tests. Engineering Failure Analysis, 2009, 16: 1533-1541

[11] R. Raju:Evaluation of fatigue life of aluminum alloy wheels under bending loads. Fatigue and Fracture of Engineering Materials and Structures.2009, 32:119-126

[12] M. Guo:Clamp load consideration in fatigue life prediction of a cast aluminum wheel using finite element analysis.SAE Technical Paper 2004,(1):1581

[13]P.R.Raju, B.Satyanarayana, K. Ramji :Evaluation of fatigue life of aluminum alloy wheels under bending loads. Fatigue \& fracture of engineering materials \& structures. 2008.01316:119-126

[14]U. Kocabicak, M.Firat:Numerical analysis of wheel cornering fatigue tests.Engineering Failure Analysis. 2001,8(4):339-354

[15]P.Lia, D.M.Maijerb, T.C.Lindleya:A through process model of the impact of in-service loading, residual stress, and microstructure on the final fatigue life of an A356 automotive wheel. Materials Science and Engineering.2007,460 461:20-30

[16] G. Hua, M.W.Brown:Multi-axial fatigue. Journal of Mechanical Strength, 1996,18(1):9-13

[17] M,W.Brown, K.J.Miller:A theory for Fatigue Failure Multiaxial Stress-strain Conditions.Pron.Inst.Mech.Engs.1973:745-755

[18] W.Lei, W.Dejun:Life prediction approach for random multiaxial fatigue. 2003(2),25:204-206 